\title{
A STUDY ON CLOSURE OF TYMPANIC MEMBRANE BY 10\% TCA
}

\author{
Sathi Raju Velaga S. S. P1, Krishna Chaitanya V², Gowthami Sandhya D \\ ${ }^{1}$ Consultant and Assistant Professor, Department of ENT, KIMS, Andhra Pradesh. \\ ${ }^{2}$ Consultant and Associate Professor, Department of ENT, Narayana Medical College, Nellore. \\ ${ }^{3}$ Consultant, Department of Bio-Chemistry, Srinivasa ENT Hospital, Kakinada.
}

\begin{abstract}
Purpose of closure of central perforation of Tympanic Membrane is to restore continuity and restore hearing.(1) this study was carried on 50 patient with small dry central perforation over a duration of two years with success rate of seventy seven percentage and 5-6\% dB hearing improvement.
\end{abstract}

KEYWORDS: BPSK Modulator, Convolutional Encoder, CORDIC, DS-CDMA/CI, FPGA.

HOW TO CITE THIS ARTICLE: Sathi Raju Velaga S. S. P, Krishna Chaitanya V, Gowthami Sandhya D. "A Study on Closure of Tympanic Membrane by 10\% TCA". Journal of Evolution of Medical and Dental Sciences 2015; Vol. 4, Issue 89, November 05; Page: $15440-15442$, DOI: $10.14260 /$ jemds/2015/2204.

INTRODUCTION: Chronic supportive otitis media is most common problem in India.(1) various methods have been advocated from decades mostly surgical i.e. tympanoplasty. ${ }^{(2)}$ but for small central perforation closure can be done with $10 \%$ trichloro acetic acid which was advocated by okonuff in 1895 and was still popular.(3)

AIMS: The main purpose of this study to see the success rate in closure of small perforations and also in patients with associated ENT problems like deviated nasal perforation, allergic rhinitis.

MATERIALS AND METHODS: This study was done in Srinivasa ENT hospital, Kakinada during period of Nov 2012 to No 2014 with sample size of 50 patients and with 6 month follow up.

\section{Inclusive Criteria:}

- Dry small central perforation for 6 weeks mild to moderate conduction hearing loss.

- Normal eusthasian tube function.

- Traumatic perforation.

- Residual perforation in post myringoplasty.

\section{Exclusion Criteria:}

- Subtotal and total perforation large central perforation.

- ASOM.

- Otosclerois.

- Atticoantral perforation.

Patients selected are completely evaluated with otoscopy, diagnostic nasal endoscopy and pure tone audiometry.

Informed written consent taken from patients.

Financial or Other, Competing Interest: None.

Submission 11-10-2015, Peer Review 12-10-2015,

Acceptance 21-10-2015, Published 04-11-2015.

Corresponding Author:

Dr. Sathi Raju Velaga,

D. No. 3-20-4/2/1,

Road No-9, Rammohan Raja Nagar,

Kakinada.

E-mail: drsathirajuvelaga@gmail.com

DOI: $10.14260 /$ jemds/2015/2204.
Preparation of TCA: It is prepared by mixing 10grams of $100 \%$ TCa with $10 \mathrm{ml}$ of distilled water.(4.5)

Procedure was done under local anesthesia with $4 \%$ xylocane on tympanic membrane with cotton ball for 30 minutes, ${ }^{(6)} 10 \%$ TCA is kept on the rim of tympanic membrane with care taken not to scar promontory.(7)

Procedure repeated after every 10-14 days after closure PTA is done.(8)

DISCUSSION: Perforation of the tympanic membrane causes a conductive hearing loss.(9) Perforation induced losses are greatest at lowest frequencies. Larger perforations result in larger hearing losses. Identical perforations in two different ears have conductive losses that can differ by up to $20-30 \mathrm{db} \cdot(10,11)$ The tendency of even very large perforation of the tympanic membrane to heal spontaneously was noted as early in 1876 by Roosa. ${ }^{(4,12)}$ In 1851 Toynbee demonstrated five distinct layers of the pars tensa of the tympanic membrane as follows. $(1,13):$

1. An outermost epidermis.

2. Dermis of fibrous tissue, blood vessels and nerves.

3. Outer radiate fibrous layer.

4. Inner circular fibrous layer.

5. Innermost thin mucosal layer.

A large perforation of the tympanic membrane heals often into a thin atrophic scar which lacks the fibrous layers, having only an outer epidermis and inner mucosal layer.(4,13) This may rupture easily by external trauma, forcible inflation of the Eustachian tube and in otitis media. But a perforation closed by repeated acid cautery of the rim usually results in a normal appearing tympanic membrane with all the five layers.(14)

Histo pathological study of a newly formed perforation shows proliferation of squamous epithelium within 12 hours at the edge of the perforation, granulation formation within 18 hours, while the inner mucosa of the membrane takes several days to regenerate. $(7,14)$ In chronic tympanic membrane perforation, squamous epithelium is found adjacent to the middle ear mucosa and creates a perforation edge with no raw surface. This is a contributing factor for a perforation to persist and was observed by Dunlop and Schuknecht in 1947. $(6,15,16)$

The principle of chemical cauterization is that when on application, it breaks up fibrosis, promotes granulation and new tissue formation at the margin of the perforation. The patch acts as a splint to bridge the margins of the perforation. Given a flat surface, the epithelium grows at the rate of $1 \mathrm{~mm}$ per day. 
Three guidelines to promote healing of perforation by acid cautery of the rim.(17,18,19):

1. The outer squamous epithelium that has grown inward across the edges must be destroyed repeatedly, to permit fibroblastic proliferation of the fibrous layer.

2. The rim of the perforation should be kept moist as drying immediately kills the young fibroblasts.(20,21)

3. Hyperemia stimulates fibroblastic proliferation and should be induced by mild irritation.

Myringoplasty may be recommended as a first attempt for perforations involving more than $65 \%$ of the pars tensa. $(22,23)$ for narrow external canal preventing a view of the anterior edge of the perforation and for patients who refuse to come for repeated follow up.

In the literature, various methods have been used other than chemical cautery, in the non-surgical closure of perforations, like the irritant oil method, fibrin glue, fat plug, carbon dioxide laser trimming of the margins before applying paper patch etc. $(24,25)$

Juers reported an $88 \%$ success with an average of 3.7 applications. $(26,27) \mathrm{He}$ had further everted the margins of the perforation under the operating microscope, whereas Derlacki who reported $75 \%$ success in office treatment at biweekly intervals had used cautery alone.(8) Dunlop had a $100 \%$ success with 3-33 treatment at biweekly intervals. ${ }^{(28)}$

In the present study, it was noted that the highest success was seen among patients with traumatic perforations and in residual perforations, lowest in those patients with allergic rhinitis. This study gave an overall success rate of $77 \%$, which is comparable with the previous studies documented in the literature and hearing improvement of about 5 to $6 \mathrm{db} .(29)$

CONCLUSION: Various studies on the subject of cauterizing of tympanic membrane perforations, it may be considered as a first line in the management of small to moderate sized perforation before attempting surgical closure. The present study with $77 \%$ success rate and $5-6 \mathrm{~dB}$ hearing improvement has led to the following conclusions:

1. Smaller perforation without other ENT causes has better the closure rate.

2. Traumatic perforation, had a better healing rate.

3. Safely tried in patients with systemic medical conditions and in whom surgical intervention is contraindicated.

Apart from the fact that multiple sittings is required which is a disadvantage, this procedure of chemical cautery of the tympanic membrane perforation is a relatively safe, simple, and economical technique. As it can be done as an outpatient procedure with minimal sophisticated equipments.

\section{REFERENCES:}

1. Gulya AJ, Glasscock ME. Glasscock-Shambaugh surgery of the ear. 5. Spain: BC Decker Inc; 2003. pp. 400-420.

2. Shambaugh GE. Glassscock, Shambaugh surgery of the ear. 2. Philadelphia: W.B. Saunders Company; 1967. pp. 429-437.

3. Marra S, et al. Effectiveness of non-surgical closure of tympanic membrane pars tensa perforation. Ear Nose Throat J. 2002; 81(8):556-558. [PubMed].
4. Upal KS. Closure of tympanic membrane perforation by chemical cautery. IJOL HNS. 1997; 49:151-153. [PMC free article] [PubMed].

5. Wright WK. The repair of chronic central perforations of the tympanic membrane: by repeated cautery; by skin grafting. Laryngoscope. 1956; 66(11):1464-1487. Doi: 10.1002/lary.5540661104. [PubMed] [Cross Ref].

6. Dorsun E. Comparison of paper-patch, fat, and perichondrium myringoplasty in repair of small tympanic membrane perforations. Otolaryngol Head Neck Surg. 2008; 138:353356. Doi: 10.1016/j.otohns.2008.01.003. [PubMed] [Cross Ref].

7. Lee SH, Lee KC, et al. Paper patch myringoplasty with carbon dioxide laser for chronic tympanic membrane perforations. Eur Arch Otorhinolaryngol. 2008; 265:1161-1164. Doi: 10.1007/s00405-008-0592-1. [PubMed] [Cross Ref].

8. Goldman NC. Chemical closure of chronic tympanic membrane perforation. ANZ J Surg. 2007; 77:850-851. Doi: 10.1111/j.1445-2197.2007.04256.x. [PubMed] [Cross Ref].

9. Kumar $\mathrm{N}$ et al. Using middle ear risk index and ET function as parameter for predicting outcome of tympanoplasty. Indian J Otolaryngol Head Neck Surg 2012; 64(1): 5-12. [DOI via Crossref] [Pubmed] [PMC Free Fulltext].

10. Shyamala R and Reddy PS. The study of bacteriological agents of chronic suppurative otitis media-Aerobic culture and evaluation. J. Microbiol. Biotech. Res2012; 2 (1):152-162.

11. Verma AK et al. Epidemiology of CSOM and deafness in a rural area and developing an intervention strategy. Indian J pediatr 1995; 62 (6): 725-729. [DOI via Crossref] [Pubmed].

12. Rupa $\mathrm{V}$ et al. CSOM: prevalence and practices among rural South Indian children. Int J Pediatr Otorhinol 1999; 48(3): 217-221. [DOI via Crossref].

13. Sood AS and Bons CS. Otitis media in school going children at Amritsar, North India. Gujarat journal of Otorhinolaryngology and Head and Neck Surgery 2012; 9(1): 23-24.

14. Wakode PT, Joshi SV and Gawarle SH. CSOM in school going children. Indian J Otolaryngol Head Neck Surg 2006; 58(2): 152- 5 [Pubmed] [PMC Free Fulltext].

15. Shaheen MM et al. Chronic suppurative otitis media and its association with socio economic factor among rural primary school children of Bangladesh. Indian J Otolaryngol Head Neck Surg 2012; 64(1): 36-41. [DOI via Crossref] [Pubmed] [PMC Free Fulltext].

16. Verma AK et al. Epidemiology of CSOM and deafness in a rural area and developing an intervention strategy. Indian J pediatr 1995; 62 (6): 725-729. [DOI via Crossref] [Pubmed].

17. Daly KA. Epidemiology of otitis media. Otolaryngol Clin North Am1991; 24(4): 775-786. [Pubmed].

18. Mann SBS, Grewal BS, Nanar MS and Mehra YN. Incidence of CSOM in general population: A rural survey. Indian J Otolaryngol 1976; 28: 35- 40.

19. Tai CF, Ho KY and Juan KH. Age and prognosis of tympanoplasty type- 1 . Kaoshsiumg journal of medical science 1998; 14 (9): 542-7.

20. Sethi A, Singh I, Agrawal AK and Sareen D. Peumatization and tubal function. Indian J Otolaryngol Head Neck Surg 2005; 57 (4): 283-6 [Pubmed] [PMC Free Fulltext]. 
21. Yadav SPS, Aggarwal N, Julaha M and Goel A. Endoscopeassisted myringoplasty. Singapore Med J 2009; 50(5): 510-514. [Pubmed].

22. Sengupta A and Basak B. A study on outcome of underlay, overlay and combine technique of myringoplasty. Indian J Otolaryngol Head Neck Surg 2012; 64(1): 63-66. [DOI via Crossref] [Pubmed] [PMC Free Fulltext].

23. Derlacki et al. Repair of central perforations of tympanic membrane. Archieves of Otolaryngology 1953; 58: 405 420 [DOI via Crossref].

24. Shetty SK, George A, Kumar S and Kumar R. Management of central perforation of tympanic membrane by chemical cauterisation using tri-chloro acetic acid. Gujarat Journal of Otorhinolaryngology and Head \& Neck Surgery 2010; 7(1): 21- 24.

25. Goldman NC, Chemical closure of chronic tympanic membrane perforations. ANZ J Surg. 2007; 77(10):850 1. [DOI via Crossref] [Pubmed].
26. Bhadouriya S, Srivastava M, Gaur S, Lavania Aand Saxena R. A study of chemical cauterisation of tympanic membrane perforation by using trichloroacetic acid. International Journal of Institutional Pharmacy and Life Sciences 2012; 2(2): 195- 204.

27. Lee P, Kelly G, and Mills RP. Myringoplasty. Does the size of the perforation matter? Clinical Otolaryngology and Allied Sciences 2002; 27(5):331-4. [DOI via Crossref].

28. Wasson JD, Papadimitriou CE and Pau H. Myringoplasty, impact of perforation size on closure and audiological improvement. Journal of Laryngology \& Otology 2009; 123: 973 \& \# 8211; 977.

29. Lpu ZC, Hu YX and Tang YM. Effect of treatment at different time intervals for traumatic tympanic membrane perforation on the closure. Acta Oto-Laryngologica 2011; 131(10):10321039. [DOI via Crossref] [Pubmed]

\section{STATASTICS:}

\begin{tabular}{|c|c|c|c|c|c|}
\hline Age IN YEARS & Male & Female & Total & Closure & Percentage \\
\hline $15-20$ & 16 & 8 & 24 & 19 & $79.2 \%$ \\
\hline $21-25$ & 4 & 2 & 6 & 5 & $83.3 \%$ \\
\hline $26-30$ & 4 & 10 & 14 & 11 & $78.6 \%$ \\
\hline $31-35$ & 4 & 2 & 6 & 4 & $66.6 \%$ \\
\hline \multicolumn{7}{|c|}{ Table 1: Age wise distribution and closure rate } \\
\hline
\end{tabular}

\begin{tabular}{|c|c|c|c|}
\hline Sex & No & Closure & Result \\
\hline Male & 28 & 21 & $75 \%$ \\
\hline Female & 22 & 18 & $81-8 \%$ \\
\hline \multicolumn{3}{|c|}{ Table 2: Sex wise closure } \\
\hline
\end{tabular}

\begin{tabular}{|c|c|c|c|}
\hline Etiology & No. of patients & Closure & Result \\
\hline Inflammatory & 45 & 34 & $75.5 \%$ \\
\hline Traumatic & 3 & 3 & $100 \%$ \\
\hline Residual perforation & 2 & 2 & $100 \%$ \\
\hline \multicolumn{3}{|c|}{ Table 3: Etiology wise closure rate } \\
\hline
\end{tabular}

\begin{tabular}{|c|c|c|c|}
\hline Cause & No. of patients & Closure & Result \\
\hline Deviated nasal septum & 8 & 6 & $75 \%$ \\
\hline Allergic rhinitis & 7 & 3 & $42.8 \%$ \\
\hline \multicolumn{3}{|c|}{ Table 4: Closure rate associated with other ENT causes } \\
\hline
\end{tabular}

\begin{tabular}{|c|c|c|c|}
\hline Sex & Pre PTA & Post PTA & Improvement \\
\hline Male & $21 \mathrm{db}$ & $16 \mathrm{db}$ & $5 \mathrm{db}$ \\
\hline Female & $23 \mathrm{db}$ & $17 \mathrm{db}$ & $6 \mathrm{db}$ \\
\hline \multicolumn{4}{|c|}{ Table 5: Pre and post audiometry } \\
\hline
\end{tabular}

